\title{
Energy interaction of two-link converters of a multi-motor drive with mains supply
}

\author{
Rishat Ganiev ${ }^{1, *}$ \\ ${ }^{1}$ Kazan National Research Technological University, Institute of chemical technology 423570 Builders Avenue, 47, Nizhnekamsk, \\ Republic of Tatarstan, Russian Federation
}

\begin{abstract}
It is known that the total power electrical loads consume from the mains is the sum of their two components - active and reactive. Most electric drives of modern industrial enterprises consume up to $40 \%$ of reactive energy in relation to the total energy. This results in an increased full power consumption thereby increasing the load on the supply mains. Modern electric drives are built as follows: supply mains rectifier-direct current link-inverter - asynchronous motor. The total power consumption is at the "mainsrectifier" interface, where the required active power factor of the converter can be formed. The higher the active power factor, the lower the reactive component in the total consumed energy. Thus, the paper proposes a solution to the problem of building highly efficient converting devices for powering electric motors with the required power factor. In particular, the paper discusses possible increase in the power factor of the electric drive mains input with two-link frequency converters based on active (controlled) rectifiers with current and voltage inverters. The author proposes new ways to control active rectifiers based on the use of AC rectifying devices with fully controlled GTO, GCT thyristors, as well as pulse-width control IGBT transistors. The paper offers options for the construction of these rectifiers and the results of modeling the proposed control methods, confirming a decrease in the passive components of the mains current, and, as a consequence, an increase in the mains input power factor. The simulation results were obtained in MathLab 10, and are the basis for confirming the method of increasing the active power factor at the mains input of a controlled two-link frequency converter.
\end{abstract}

\section{Introduction}

Electric drives of modern mechanisms at industrial enterprises are the main electricity consumers. Up to 70 percent of all power consumption is accounted for the electrical drives of process plants. Most electric drives are $\mathrm{AC}$ powered, and their motors, being activeinductive mains loads, consume significant reactive power, increasing the total mains electricity consumption and reducing the overall power factor. Publications [1-4] offer a solution to this problem through the use of compensation filters and installing static capacitor banks. However, these methods lead to an increase in the cost of electrical plants and require the development of additional designs and technical solutions for their implementation in production mechanisms. In this regard, this paper proposes the development of converting devices with the required power factor, at the level of converting the alternating mains current into the direct inverter supply current.

The above circumstances and the emergence of lockable semiconductor valves served as the basis for the development of a new power asset, an active rectifier (AR). The name AR reflects this device's capability to actively influence the converter energy balance with the mains supply. [5, 6]
This work aims at developing an AR capable of maintaining the converter's electromagnetic compatibility with the mains supply, assuming complete elimination of passive components in the mains input power, taking into account the increase in the converter power factor and input reactive power compensation.

In conditions of sinusoidal mains voltage, passive components of the total power include the fundamental harmonic reactive power and the distortion power caused by the higher harmonics of the consumed current. These measures mean the consumed current minimization, since only the active component of the first harmonic power remains in the energy balance of a fully compensated converter's mains input.

The development novelty lies in the use of fully controlled rectifier properties: the integral value of AR active power averaged over the mains period can be positive - in rectifier mode, or negative - in inverter mode of converter operation. If necessary, the AR functional capabilities allows both eliminating and generating passive power components in order to compensate for similar components of other loads in the common main.

\footnotetext{
* Corresponding author: n7007@mail.ru
} 


\section{Energy modes in the "AR - mains supply" system operation}

The study of a multi-motor electric drive of the cord line shown in $[5,7]$, which includes reversible frequency converters, implies the use of active (controlled) rectifiers (AR) as the first control link. It has been shown that changes in the AR energy mode of any drive do not have any effect on the currents and speeds of any other drive, but can affect the power factor at the mains input and thus affect the current consumption, increasing or decreasing it. The existence of a particular energy regime depends on the adopted switching algorithm in the AR circuit. Their development should proceed from the finite speed and frequency properties of the lockable valves. The list of solutions considered in this chapter assumes the AR operation at a relatively low (basic) switching frequency determined by the rectifier pulse rate $\omega_{n}=m_{1} \omega_{1}$. In this regard, an example of using the algorithms under consideration is ARs based on lockable thyristors such as GTO, GCT, IGCT, which differ from power transistors in a lower frequency bandwidth $[6,7$, $8]$.

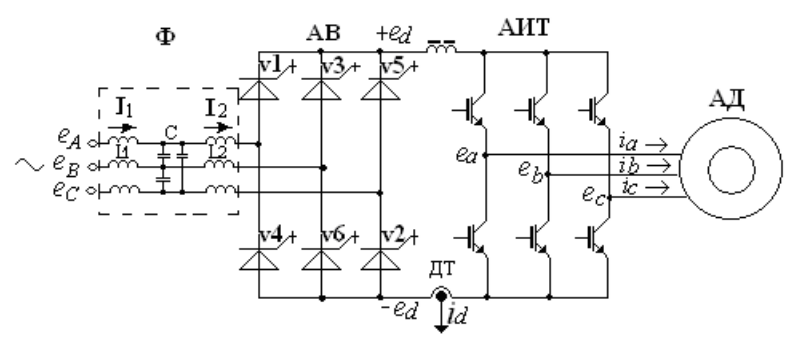

Fig. 1. AR based on gate turn-off thyristors as part of a twolink frequency converter with a standalone current inverter.

The disadvantages of the traditional method of pulsephase thyristor adjustment at the fundamental frequency are known. Among them is the impossibility to influence the ratio of the input and output AR circuit currents by means of controls. The reason is the minimum amount of control coordinates (degrees of freedom) in the form of a single parameter - the thyristor switching-on angle $\alpha$, which leads to a rigid binding of the consumed mains current $I_{l}$ to the rectified load current $I_{d}$. The novelty of the considered method of autonomously adjusting the active and reactive AR mains current components follows from the possible change in both the angles of GTO switching-on $\left(\alpha_{1}\right)$ and switching-off $\left(\alpha_{2}\right)$ during each half-wave of the rectified voltage. Let us show that the result can be the controlled electric drive operation at a minimum mains current in steady-state modes or limiting the surges of this current in transient modes of a valve electric drive operation.

\section{Method of controlling GTO-based AR}

The choice of an energetically efficient AR control method should take into account the capability of valve elements to distort the mains current waveform, and in case the converter and mains powers are commensurable, these distortions also apply to the mains voltage. The generalized energy indicator, taking into account the influence of amplitude and phase distortions of the consumed current, is the power factor $\mathrm{KM}$ expressed with a sinusoidal mains voltage waveform as follows:

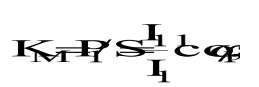

where is the effective value and phase shift of the primary (mains) rectifier's current fundamental harmonic. From (7.3) it follows that an increase in $K_{m}$ in AR circuits can be achieved only by excluding passive, that is, unproductive components of the total power $\mathrm{S}$ from the energy balance. The most important result of increasing $K_{M}$ is to reduce the RMS current consumption $\mathrm{I}_{1}$ at the mains input of the converter. However, if AR operates on a motor load, identification of the specificminimum mains current using (1) turns out to be difficult, since the currents $I_{11}, I_{1}$ are a secondary function of the rectified load current $I_{d}$. It is known that in an electric drive, the minimum current consumption is set by the rectified load current $I_{n}=I_{d}$ that generates the electromagnetic torque.

Reduced to the mains input, this current can serve as a criterion for the comparative analysis of switching algorithms in the AR circuit based on current consumption. In this regard, a more acceptable indicator of the algorithm energy efficiency should be considered the current utilization factor in the form of the ratio of the RMS mains current to the average rectified load current. $[9,10]$ The equality of active powers of the mains input and the rectifier load on ideal keys allows to establish the relationship of this indicator with the power factor.

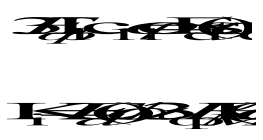

It is not difficult to notice that for traditional pulsephase rectifier control, changes in the control angle $\alpha=0 \div \pi / 2$ are accompanied by the same relative changes in $\mathrm{E}_{\mathrm{d}}(\alpha)$ and $\mathrm{K}_{\mathrm{m}}(\alpha)$, as a result, the coefficient of thyristor rectifiers' current consumption with phase control remains unchanged $\mathrm{K}_{\mathrm{i}}=$ const. In particular, for a 3-phase bridge rectifying circuit, we obtain the known value. The constancy of $\mathrm{K}_{\mathrm{i}}$ indicates that the decrease in rectified EMF and load power achieved at $\alpha \rightarrow \pi / 2$ occurs at a constant consumption current at the mains input of the electric drive. The reason for this property of phase control at $\alpha=$ var, $I_{d}=$ const follows from changes in the active and reactive components of the mains current in mutually opposite directions. In other words, the decrease in the active component of the mains input current is compensated by the increase in its reactive component. This conclusion confirms the impossibility of increasing $\mathrm{K}_{\mathrm{i}}$ for traditional control of thyristor rectifiers. As already noted, the use of lockable valves allows resorting to other methods, leading to the desired 
decrease in the current load of the mains as the rectified voltage decreases.

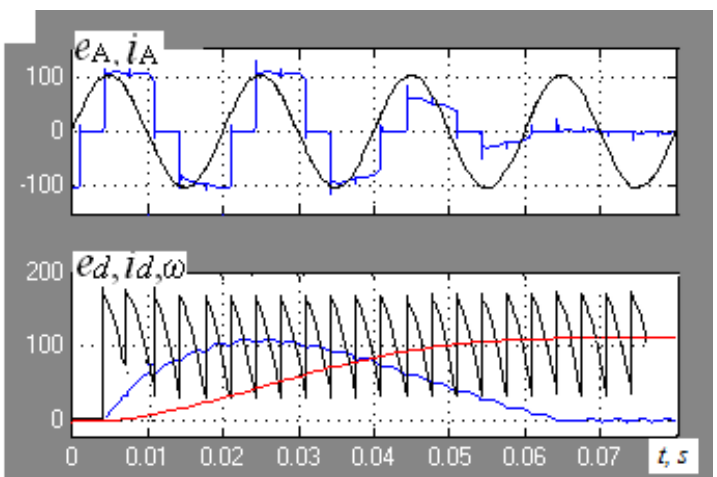

Fig. 2. Diagrams of mains $e_{A}, i_{A}$ and rectified $e_{d}, i_{d}$ voltage and current, as well as motor shaft speed $\omega(\mathrm{t})$ at the AR output in the starting mode with the traditional key control method.

Fig. 2 and Fig. 3 show the results of computer simulation which allow comparing the current consumption of a valve electric drive in the starting mode with the traditional (Fig. 2) and modified (Fig. 3) valve switching algorithms.

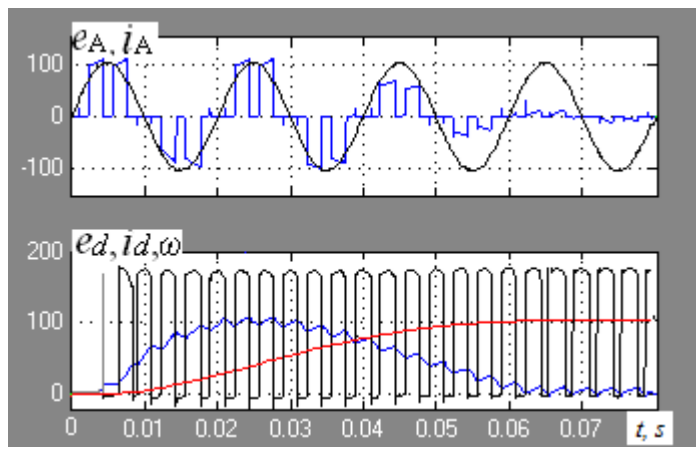

Fig. 3. Diagrams of mains $e_{A}, i_{A}$ and rectified $e_{d}$, $i_{d}$ voltage and current, as well as motor shaft speed $\omega(\mathrm{t})$ at the AR output in the starting mode with the modified key control method.

The modified method consists in load connection to the mains source alternating with the main frequency and its subsequent bypassing with antiphase valves of the AR bridge circuit. For the purpose of correctness, the curves of consumed current in phase A of the mains $i_{1}(t)=i_{A}(t)$ are compared with the same surges of the anchor's starting current $i_{d}(t)$ and the steady shaft speed $\omega(t)$.

\section{IGBT-based ARs with PWM control}

Unlike GTO thyristors, transistor keys such as IGBT and MOSFET have greater speed and are therefore capable of operating at a higher switching frequency. Let's show that due to this property, transistor key-based AR (for example, as shown in Fig. 4) result in the desired input and output AR current waveforms with the modulation method. Rectified voltage $e_{d}(t)$ is generated by alternating connection of output AR clamps to linear mains voltages of two levels: the upper level of the relative magnitude of $0.86-1.0$ and the average level (0.5-0.86). Restricted within these limits, the range of control is in most cases sufficient to maintain the permanent current at the AR output, assuming that the basic functions of output voltage and frequency control are performed with the AR.

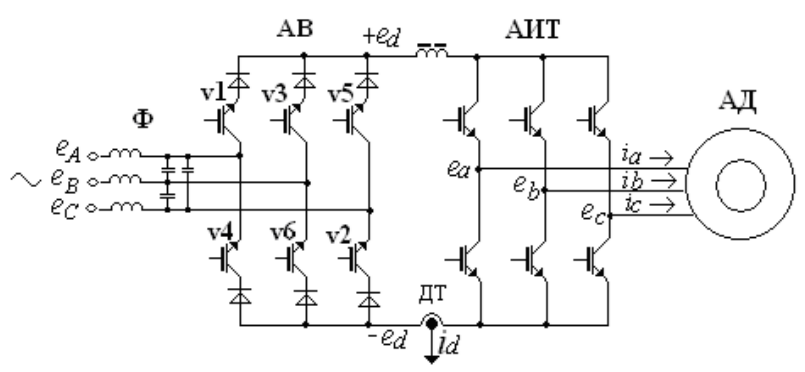

Fig. 4. IGBT transistor-based AR with protective diodes as part of a two-link frequency converter with a standalone current inverter.

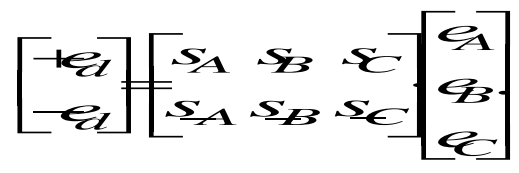

To solve the problem of electromagnetic compatibility, switching transistor keys with these pulses should lead to a continuous quasi-sinusoidal waveform of currents at the mains input and a fairly smooth current at the AR output. Diagrams in Fig. 5 show one of the solutions to this problem based on high-frequency pulsewidth control (PWC) of the rectified voltage. This method involves the generation of primary pulses $f$ as a result of comparing the control $\mathrm{x}(\mathrm{t})$ and the reference хоп $(\mathrm{t})$ signals, followed by their distribution by transistors according to the logical equation:

$$
\left[\begin{array}{l}
s_{A} \\
s_{A} \\
s_{B} \\
s_{B} \\
s_{C} \\
s_{C}
\end{array}\right]=\left[\begin{array}{lll}
\left(s_{C B}+s_{B C}\right) & \left(s_{A B}+s_{A C}\right) & \left(s_{A C}+s_{A B}\right) \\
\left(s_{B C}+s_{C B}\right) & \left(s_{B A}+s_{C Z}\right) & \left(s_{C A}+s_{B A}\right) \\
\left(s_{A C}+s_{C A}\right) & \left(s_{B C}+s_{B A}\right) & \left(s_{B A}+s_{B C}\right) \\
\left(s_{A C}+s_{C A}\right) & \left(s_{A B}+s_{C B}\right) & \left(s_{A B}+s_{C B}\right) \\
\left(s_{A B}+s_{B A}\right) & \left(s_{C B}+s_{C A}\right) & \left(s_{C B}+s_{C A}\right) \\
\left(s_{A B}+s_{B A}\right) & \left(s_{A C}+s_{B C}\right) & \left(s_{B C}+s_{A C}\right)
\end{array}\right]\left[\begin{array}{l}
f \\
f \\
1
\end{array}\right]
$$

Where $\mathrm{s}_{\mathrm{AB} 1}, \mathrm{~s}_{\mathrm{CB} 2}, \ldots \mathrm{s}_{\mathrm{AC} 2}$ are synchronizing pulses that divide the semi-period of mains voltage into six equal intervals. An advantageous feature of this algorithm is the increased interval of the active state of each valve in the mains period, at maximum being equal to $\lambda=\pi$ instead of $\lambda=2 \pi / 3$, with the traditional pulse-phase control method $[11,12]$. As can be seen from the diagrams in Fig. 5, the result is the elimination of the zero pauses $(\pi / 3)$ in the mains current, traditional for three-phase bridge circuit.

The results of the IGBT transistor key-based AR simulation and the proposed control method are shown in Fig. 5. 


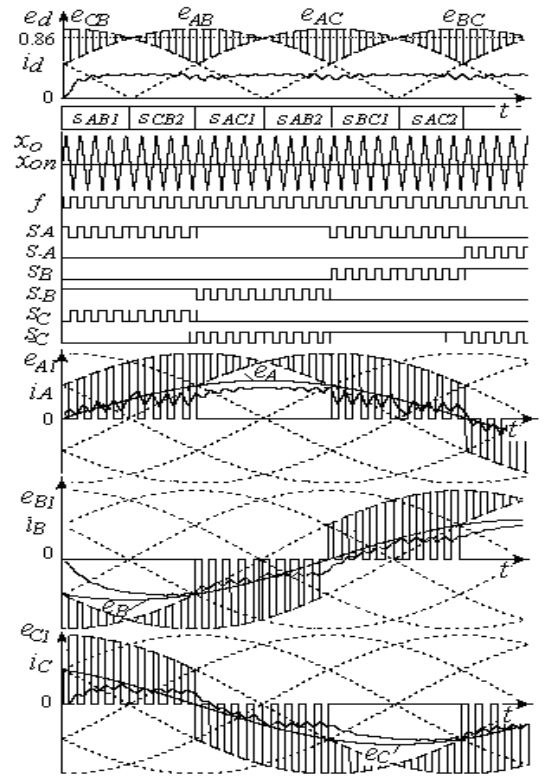

Fig. 5. Transistor key control processes in the AR circuit.

\section{Conclusions}

Analysis of the diagrams has shown that periodic load bypasses for GTO thyristor-based AR (Fig. 3) contribute to eliminating the reactive component in the mains current, in the form of a decrease in the ampere-second areas under the curve of current $i_{A}(t)$. The area under the current curve characterizes the RMS current value. Visual evaluation of the curves shows that the RMS value of consumed current $\mathrm{I}_{1}$ with a modified AR key control decreases by at least $30-50 \%$.

With the use of IGBT transistors (Fig. 5), voltages are generated under the effect of two types of modulation: amplitude - on the part of the mains supply, and pulse-width - on the part of the DC link. The positive effect of amplitude modulation leads to coincidence of the basic voltage harmonics with voltages of the mains phases $\mathrm{e}_{\mathrm{A}}(\mathrm{t}), \mathrm{e}_{\mathrm{B}}(\mathrm{t}), \mathrm{e}_{\mathrm{C}}(\mathrm{t})$ in time and waveform. The curves of phase currents $i_{A}(t), i_{B}(t), i_{C}(t)$ in Fig. 5 show the response of the active-inductive circuit to these voltages, confirming possible approximation of the mains current waveform to the waveform of mains phase voltages by increasing the transistor key switching frequency.

Both of the above methods lead to the increase in $\mathrm{K}_{\mathrm{m}}$ which is confirmed by the reduction of the full current $I_{1}$, due to elimination of the reactive current components.

\section{References}

1. Pisupati Sadasiva Subramanyam, Reactive Power Compensation, Conference: Sent to HOD,EEE Dept, for Internal Presentation in EEE Association, VBIT, Hyderabad (April 2019)

2. A. Skamyin, A.A. Belsky, Reactive power compensation considering high harmonics generation from internal and external nonlinear load, IOP Conference Series Earth and Environmental Science, 87 (3), 032043

3. S. Bhattacharya, B. Fardenesh, B. Shperling, S. Zelingher, Convertible static compensator: Voltage source converter based facts application in the New York $345 \mathrm{kV}$ transmission system, Int. Power Electronics Conf. (IPEC 2005), 2286-2294 (2005)

4. J. Dixon, L. Morán, J. Rodríguez, A. Domke, Reactive Power Compensation Technologies: State-of-the-Art Review, Proceedings of the IEEE, 93 (12) (December 2005)

5. R. Ganiev, Cordline multi-motor electric drive with energy recovery, E3S Web of Conferences, 178 (9), High Speed Turbomachines and Electrical Drives Conference, HSTED 2020, Prague, Czech Republic, 14-15 May 2020, code 162052, 01023 (July 2020)

6. S.N. Sidorov, Active converters of direct type on diode-transistor modules, Electrical Motorering, 4 (2004)

7. R. Ganiev, Reversible frequency converters in the composition of multimotor electric drives, IOP Conference Series: Materials Science and Engineering, International Scientific Electric Power Conference, 23-24 May 2019, Saint Petersburg, Russian Federation, 643, 012068

8. J.E. Valdez-Resendiz, J.C. Mayo-Maldonado, A. Llamas-Terres, J.C. Rosas-Caro, Quadratic boost converter based on stackable switching stages, IET Power Electronics, 11, 8 (2018)

9. R. Ganiev, Two-way conductivity converters in the technology of tire cord rubberization, E3S Web of Conferences, Sustainable Energy Systems: Innovative Perspectives, SES-2020, Saint Petersburg, Russian Federation, 29-30 October 2020, 220, 01069

10. S.N. Sidorov, Control algorithms of twooperation valves in transducers with direct connection, Electrical Motorering, 5 (2001)

11. A. Rehaoulia, H. Rehaoulia, F. Fnaiech, Output voltage quality analysis of three-phase multilevel inverters, Electrical Motorering (Archiv für Elektrotechnik), 100 (2) (2018)

12. A. Dendouga, R. Abdessemed, M.L. Bendaas, Active and reactive powers control of a doublyfed induction generator fed by matrix converter, EPE Journal (European Power Electronics and Drives Journal), 19 (1) (2009)

13. S. Zambou, R. Nuessl, F.M. Azeutsap, S.S. Zekeng, J.M. Ndjaka, B. Magunje, S.D. Walton, E.O. Jonah, M. Harting, D.T. Britton, Switching alternating current (ac) using a fully screen-printed current-driven transistor, IET Power Electronics, 11 (1) (2018)

14. R.N. Ganiev, N.I. Gorbachevsky, V.N. Dmitriev, S.N. Sidorov, Method for controlling a two-link frequency Converter, Russian patent, Publ. IN BI \#5, 2444834 (2012) 
15. R.N. Ganiev, S.N. Sidorov, Two-link frequency Converter with lockable valves, Russian patent Publ. IN BI \#5, 2461115 ( 2012)

16. S.N. Sidorov, R.N. Ganiev, System of frequencycurrent control of an electric drive based on lockable valves, Drive technology, 1 (2011)

17. Active bridge dc-dc converter, Active filtering of dfig stator and rotor current harmonics caused by distorted stator voltages, European Power Electronicsand Drives Journal, 21 (1), 43-54 (2011)

18. N. Al-Sheakh Ameen, A.A. Naassani, R.M. Kennel, Design of a digital system dedicated for electrical drive applications, EPE Journal (European Power Electronics and Drives Journal), 20 (4) (2010)

19. M. Cacciato, A. Consoli, G. Scarcella, G. Scelba, Indirect maximum torque per ampere control of induction motor drives, EPE Journal (European Power Electronics and Drives Journal), 18 (4), 34-41 (2008)

20. P. Záskalický, Mathematical model of a fivephase voltage-source pwm-controlled inverter, Electrical Motorering (Archiv für Elektrotechnik), 99 (4) (2017) 